\title{
Water supply-demand:quantity, quality and price of the water conjunctive use
}

\section{Opinion}

Water, has long life as the Earth, is composed of simple elements with complicated characteristics for diversified applications not only life needed but also high-technology. There are three items for water, quantity, quality, and price, and three functions on people's livelihood need, agriculture, and industry. Because of its irreversibility, the recycling becomes obviously important for sustainability. Whether the water supply is sufficient or not is deeply sensitive to people's water values on their customs and due to the uncertainty of water cycling, especially the quantity, as Figure 1 both on spatial and time. We firstly pay much attention on this item "quantity" and its concerned problem "sufficiency". Surface water and ground water are varied on seasons and the properties of geology and geography. For the solution of sufficient water quantity, some researchers, such as Laronne $\mathrm{J}$ et al. ${ }^{1}$ focused on surface water characterization; Robert M Delinom ${ }^{2}$ paid attention to groundwater management; Alpaslan $\mathrm{AH}$ et al. ${ }^{3}$ had a research on river basin management. The topic of wetland, the interaction of surface water and groundwater, management for regional necessity could be obvious. Wang XS et al. ${ }^{4}$ supposed groundwater response to leakage of surface water through a thick vadose zone; Sahuquillo $A^{5}$ presented a research on quantitative characterization of the interaction between groundwater and surface water. Significant flood season makes the region's water resources deployment often difficult, water resources has become a key factor in economic development. In order to reduce the environmental problems of water shortage or uneven distribution, it is important and urgent to establish an integrated water resource management strategy, the joint management of surface water and groundwater management strategy will be more efficient use of water resources to play its greatest benefits, while mitigating the negative impact of supply and demand imbalances. A conceptual model of water conjunctive-use system as in Figure 2 is presented in this article. In this figure, the analyses of water quantity, quality and price are
Volume I Issue 7 - 2017

Edward Ching Ruey Luo
Asian Institute of Technology, Taiwan

Correspondence: Edward Ching Ruey Luo,Asian Institute of Technology,Taiwan, Email edward.luo@msa.hinet.net

Received: October 29, 2017 | Published: December 12, 2017

mentioned conceptually. Some key questions are needed to mention: the cost of construction for water, such as reservoirs, or rainwater from the roof through gutter snipe to the tank or basement; the cost for water quality control; the cost for the substitution use from agriculture to livelihood need. Another is the prediction of annual water quantity for industrial needed with its cost of water quality control, and the other is the recycling rate of industrial water and the corresponding cost.

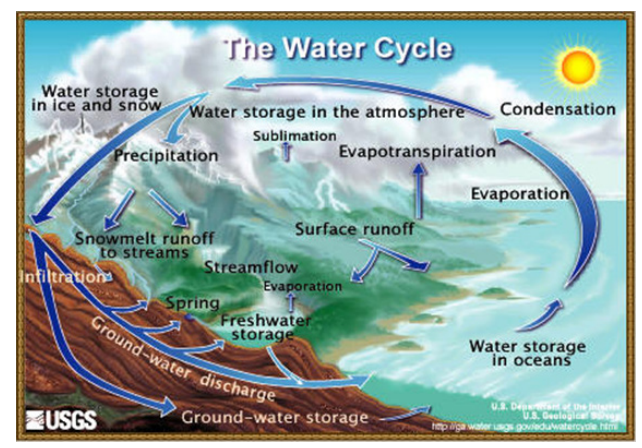

Figure I The water cycle.

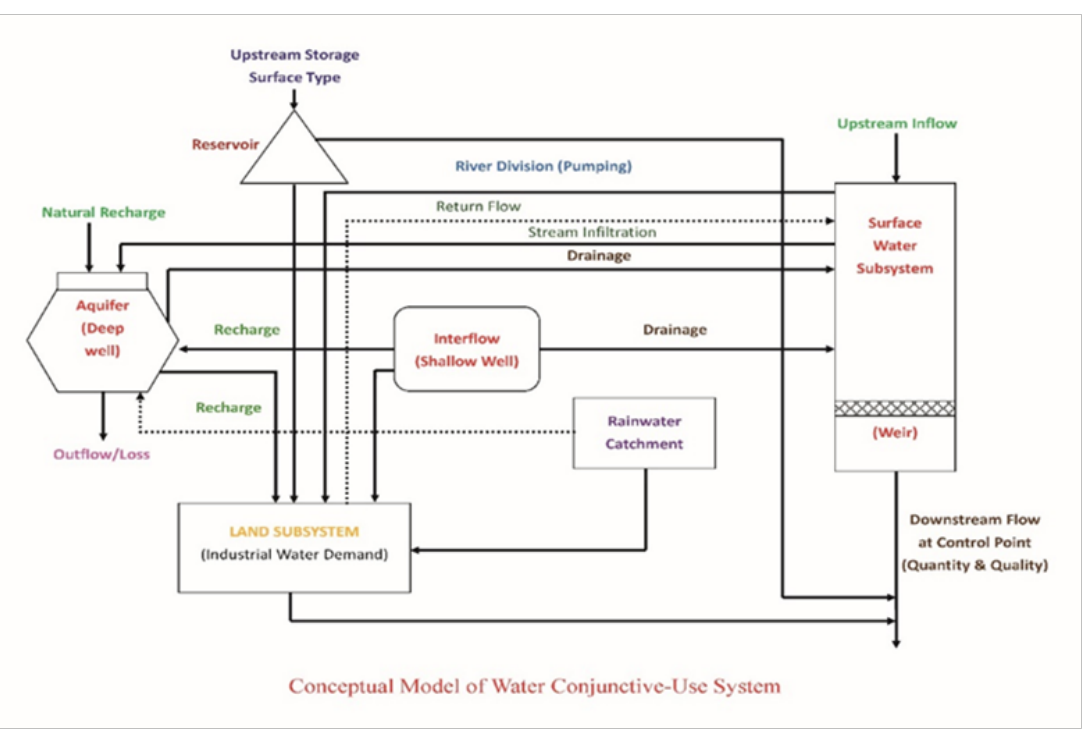

Figure 2 Conceptual model of water conjunctive-use system. 


\section{Acknowledgments}

None.

\section{Conflict of interest}

Authors declare there is no conflict of interest in publishing the article.

\section{References}

1. Laronne J, Alexandrov Y, Reid I. Surface water characterization \& utilization in the Middle East, Respectively Exemplified By Nahal Eshtemoa (Wadi Samoa) \& The Shiqma-Besor (Wadi Gaza) Reservoirs, Israel. IPCRI pub, Israel; 2004. p. 1-13.
2. Robert MD. Groundwater management issues in the Greater Jakarta area, Indonesia. Bull TERC Univ Tsukuba. 2008;8(S2):1-15.

3. Alpaslan AH, Attila A, Nedim Y. River basin management plans in Turkey during the accession period to European Union. International Congress on River Basin Management. 2007;1-19.

4. Wang XS. Groundwater response to leakage of surface water through a thick vadose zone in the middle reaches area of Heihe River Basin, in China. Hydrol Earth Syst Sci. 2010;14:639-650.

5. Sahuquillo. Quantitative characterization of the interaction between groundwater and surface water. IAHS. 1986;156:1-14. 